\title{
SYNTHESIS OF SILVER NANOPARTICLES FROM THE MEDICINAL PLANT BAUHINIA ACUMINATA AND BIOPHYTUM SENSITIVUM-A COMPARATIVE STUDY OF ITS BIOLOGICAL ACTIVITIES WITH PLANT EXTRACT
}

\author{
ELIZABATH ANTONY, MYTHILI SATHIAVELU, SATHIAVELU ARUNACHALAM*
}

School of Biosciences and Technology, VIT University, Vellore 632014

Email: asathiavelu@vit.ac.in

Received: 22 Nov 2016, Revised and Accepted: 02 Dec 2016

ABSTRACT

Objective: The aim of current study was to synthesise silver nanoparticles from the leaf extracts (aqueous and methanol) of two medicinal plants Bauhinia acuminata and Biophytum sensitivum and to compare its biological activities with that of plant extract.

Methods: Silver nanoparticles were synthesised, and it was characterised using UV-Visible spectroscopy and scanning electron microscope (SEM). Fourier transform infrared spectroscopy (FTIR) and GC-MS analysis were done for silver nanoparticle extract. The biological activities such as DPPH scavenging assay, haemolytic assay and antimicrobial assay were done for both nanoparticle and plant extract.

Results: The UV-Visible spectroscopy showed the formation of nanoparticles in a size range of 400-460 nm. GC-MS analysis showed the presence of biologically active compounds like DL-alpha-tocopherol and Alpha-tocopherol-beta-D-mannose. FTIR analysis of silver nanoparticles and leaf extracts showed the formation of aldehydes, alkenes, amines, alcohols, etc., which confirmed the presence of the compounds present in plant extracts. SEM image showed the formation of nanoparticles of size 2 micrometre. Phytochemical analysis of plant extracts showed the presence of carbohydrates, phenols, flavonoids, saponins, tannins and terpenoids. The methanol extract of Bauhinia acuminata showed high DPPH scavenging activity of $90 \%$ compared to that of the silver nanoparticle. The percentage hemolysis of all extracts was found to be $6 \%$ - $39 \%$. The antimicrobial activity of leaf extracts showed excellent activity towards Bacillus cereus and Listeria monocytogens.

Conclusion: The results of present study showed that the silver nanoparticle synthesised from the plant extract has many bioactive compounds and it was found to have significant biological activities but comparatively lesser than plant extract. It concludes the both plant and nanoparticle extract can be used as a potential resource for therapeutic purpose.

Keywords: Silver nanoparticle synthesis, Bauhinia acuminata, Biophytum sensitivum, FTIR, SEM, Antimicrobial activity

(C) 2016 The Authors. Published by Innovare Academic Sciences Pvt Ltd. This is an open access article under the CC BY license (http://creativecommons.org/licenses/by/4.0/) DOI: http://dx.doi.org/10.22159/ijap.2017v9i1.16277

\section{INTRODUCTION}

Nanoparticle synthesis from bio routed method is the growing field of bionanotechnology due to their low expensive, non-toxic nature. So this method of synthesis can be considered as economic and valuable alternative source for the synthesis of silver nanoparticles.

Medicinal plants have been in use from ancient times, and their efficacy has been increasing day by day in the current world. Naturally, acquired compounds are considered as environmentally friendly and also more effective than the synthetic drug. These medicinal Plants represent a foundation for many pharmaceutical compounds since it is comprised of many secondary metabolites which have been used in the treatment of many human diseases [1]. The phytochemical constituents present in plant materials serve as both reducing and capping agent in silver nanoparticle synthesis. The green method of nanoparticle synthesis targets mostly on silver nanoparticles as they are striving towards the edge level utilities in every aspect of science and technology including the medical fields. Colloidal silver is a current area of interest due to its distinctive properties viz, good conductivity, catalytic activity, chemical stability and antimicrobial activity [2]. The major benefit of using plant extracts for the synthesis of silver nanoparticles is that they are readily available, safe, and nontoxic and have a wide range of phytochemicals that can assist in the reduction of silver ions [3]. Silver compounds and its salts have been used as antimicrobial agents and wound care products since time immemorial [4]. Silver nanoparticles (AgNPs) have been widely studied and proved as an effective antimicrobial agent. The mechanism is similar as the metallic silver, but it is more effective as an antimicrobial agent than other silver compounds. Silver nanoparticles and silver ions released by silver nanoparticles interacts with the biomolecules contain sulphur (proteins) and phosphorus (DNA) which interrupts cellular metabolism. Recent studies highlighted that silver nanoparticles are able to generate reactive oxygen species (ROS) results in microbial membrane damage [5]. The current work emphasis on the green routed silver nanoparticle synthesis using two medicinal plants Bauhinia acuminate, Biophytum sensitivum and comparing it's biological activities with plant extracts.

\section{MATERIALS AND METHODS}

\section{Chemicals}

Ferric chloride, Hydrochloric acid, Sodium hydroxide, Sulphuric acid, Chloroform, Fehling's A, Fehling's B, Million's reagent, 1,1-Diphenyl2-picryl hydroxyl (DPPH), DMSO, Nutrient agar, Nutrient broth, Brain heart infusion agar, Potato dextrose agar, Muller hinton agar were obtained from Hi-Media Pvt Ltd. All the chemicals purchased were of analytical grade.

\section{Collection of plant material}

The leaves of Bauhinia accuminata and Biophytum sensitivum were collected from Kannur (11.8698N, 75.3555 E) and Alappuzha $(9.49 \mathrm{~N}, 76.33 \mathrm{E})$ districts of kerala, India.

\section{Preparation of leaf extracts}

The leaves of Bauhinia accuminata and Biophytum sensitivum were collected and washed thoroughly using distilled water and cut into small pieces. The leaves were shade dried for $1 \mathrm{w}$. Dried leaves were uniformly grinded using a mechanical grinder to make a fine powder. The powder was serially extracted in methanol and distilled water $(10 \% \mathrm{w} / \mathrm{v})$ using a soxhlet apparatus. These extracts were concentrated at $40 \mathrm{C}$ under reduced pressure (72mbar) with a rotary evaporator and dried using lyophilizer. Dried extracts was collected and stored in airtight container at $4 \mathrm{C}$ for further use [6]. 


\section{Nanoparticle synthesis}

Preparation of plant extracts for synthesis of nanomaterial

Finely ground powder $(10 \mathrm{mg})$ of plant material was mixed with 100 $\mathrm{ml}$ of solvents (milliQ water and methanol) and kept for incubation in a rotary shaker for 24-48 $\mathrm{h} \mathrm{[7].}$

\section{Biosynthesis of silver nanoparticles}

Biosynthesis of silver nanoparticles was followed by the method described by Pannerselvam et al. [8] with some modifications. $95 \mathrm{ml}$ of $0.1 \mathrm{mmol}$ of aqueous Silver nitrate $\left(\mathrm{AgNO}_{3}\right)$ was prepared in a conical flask, to which $5 \mathrm{ml}$ of each plant extracts were added, and the flasks were covered with aluminium foil to prevent photoreaction of silver nitrate. The reaction mix showed colour change after $30 \mathrm{~min}$, still for better synthesis the mixture was kept for incubation at room temperature for $24 \mathrm{~h}$. After incubation, nanoparticle synthesis was confirmed using UV-Visible spectroscopy and the mixture was centrifuged at $5000 \mathrm{rpm}$ for $20 \mathrm{~min}$. The resultant pellets were collected and suspended thrice in distilled water and centrifuged to remove unbound biomass residues for better Ag nanoparticles for further characterization studies. The silver nanoparticles were dried and stored.

\section{Phytochemical screening of plant extracts}

Phytochemical screening of the leaf extracts of Bauhinia acuminata and Biophytum sensitivum was carried out by following the standard protocol described by JB Harborne [9].

\section{Antioxidant assay-DPPH radical scavenging activity of plant extracts and silver nanoparticles}

The ability of the leaf extracts to obliterate the DPPH radical $(1,1$ diphenyl-2-picryl hydrazyl) was performed by the method described by Blois et al. 1958. A stock solution of leaf extracts was maintained at a concentration of $1 \mathrm{mg} / \mathrm{ml}$. From the stock solution different concentrations viz; 100, 200, 300 of plant extracts were prepared and made it to $1 \mathrm{ml}$. To this solution, $1 \mathrm{ml}$ of DPPH solution dissolved in DMSO was mixed, and the reaction mixture was incubated in the dark for 30 mints at room temperature and the absorbance was recorded at $517 \mathrm{~nm}$. Ascorbic acid was used as a standard. DMSO was used as blank. DMSO and DPPH mixture was maintained as control [10]. The same procedure was followed for the radical scavenging activity of silver nanoparticles.

The percentage DPPH, the radical scavenging activity of each extract, was done using the following formula:

$\%$ DPPH radical scavenging activity= $[(\mathrm{Ac}-\mathrm{At}) / \mathrm{Ac}]^{* 100}$

Where, Ac is the absorbance of the control (DMSO+DPPH)

At is the absorbance of the test sample.

\section{Hemolytic assay of plant extract and silver nanoparticles}

\section{Preparation of erythrocytes suspension}

Five millilitres of blood was collected from a healthy individual in a centrifuge tube containing EDTA (Ethylene diamine tetra acetic acid). The collected blood was then centrifuged at $1500 \mathrm{rpm}$ for 3-5 min. Plasma (supernatant) was discarded, and the resultant pellet was washed thrice with sterile phosphate buffer saline of $\mathrm{pH} 7.2$ by centrifugation at $1500 \mathrm{rpm}$ for $5 \mathrm{~min}$. The cells were then resuspended in $0.5 \%$ of normal saline [11].

\section{Hemolytic activity}

In vitro hemolytic activity was performed by spectrophotometer method [11]. Plant extracts were maintained in a stock solution of 1 $\mathrm{mg} / \mathrm{ml}$ in sterile phosphate buffer. Different concentrations $(25,50$, 75 and $100 \mu \mathrm{g} / \mathrm{ml}$ ) of extracts were made from the stock solution. A volume of $1 \mathrm{ml}$ of the previously treated cell suspension was added into $1 \mathrm{ml}$ of different concentration of plant extracts. The reaction mixtures were incubated at $37 \mathrm{C}$ for $30 \mathrm{~min}$. The incubated mixtures were again subjected to centrifugation at $1500 \mathrm{rpm}$ for $10 \mathrm{~min}$ in a laboratory centrifuge. The free haemoglobin in the supernatant was measured in a UV-Visible spectrometer at $540 \mathrm{~nm}$. Phosphate buffer and distilled water were maintained as a positive control and blank. The percentage hemolysis of each extract was calculated according to the following formula:

$$
\% \text { Hemolysis }=\frac{\mathrm{At}-\mathrm{An}}{\mathrm{Ac}-\mathrm{An}} \times 100
$$

Where, At is the absorbance of test sample

An is the absorbance of the positive control (phosphate buffer saline)

Ac is the absorbance of blank (distilled water)

\section{Antimicrobial activity of plant extracts and silver nanoparticles}

Bacterial strains such as Bacillus cereus (MTCC 1272), Listeria monocytogens (MTCC 657) were obtained from Microbial Type Culture Collection, Chandigarh, India. Staphylococcus aureus and Eschericia coli were obtained from Biosciences laboratory of VIT University, Tamilnadu, India. The fungal culture includes Rhizopus spp. which was isolated from spoiled food. All the cultures were maintained on their specific growth medium.

\section{Agar well diffusion assay}

Antimicrobial activity was performed by agar well diffusion method [11]. The $24 \mathrm{~h}$ fresh cultures of microorganisms were standardised using Mc-Farland turbidity assay. The culture organisms were swabbed on Muller Hinton agar (for bacteria) and potato dextrose agar (for fungi) plates. Wells were bored using sterile cork borer and $20 \mu \mathrm{l}$ of each plant extracts of $1 \mathrm{mg} / \mathrm{ml}$ concentration was pipetted out into each well. Distilled water was used as negative control. The plates were incubated at $37^{\circ} \mathrm{C}$ for $24 \mathrm{~h}$. After incubation plates were checked for the zone of inhibition. This assay was done for plant extracts as well as silver nanoparticles.

UV-visible spectroscopy characterization of silver nanoparticles

The reduction of pure AgNPs was recorded under UV-Visible spectroscopy using Shimadzu UV1800 UV-Visible spectrometer between an absorbance ranges from 300-800 nm. The UV-Visible Spectra of the plant leaf extract and silver nitrate solution were also recorded.

\section{Characterization of plant extracts and silver nanoparticles GC-MS analysis of plant extracts}

Bioactive methanol extracts of Bauhinia acuminata and Biophytum sensitivum was analysed for the presence of various compounds using the Gas chromatography-mass spectroscopy instrument. Helium was used as a carrier gas at $0.1 \mathrm{ml} / \mathrm{min}$ flow rate. The temperature of the column was programmed at $600 \mathrm{C}$ for $2 \mathrm{~min}$ ramp $106 \mathrm{C} / \mathrm{min}$ to $3000^{\mathrm{C}}$ with a holding of $6 \mathrm{~min}$. The injector temperature was maintained at $2500 \mathrm{C}$ for the analysis. The resulted peaks were identified on the basis of existing mass spectra data correlation provided from the Wiley 8. LIB and NIST08. LIB library spectrum provided by the software in GC-MS system [11].

\section{FTIR analysis of plant extracts and silver nanoparticles}

The dried plant extracts, as well as nanoparticles, were analysed by attenuated total reflectance FTIR (ATR-FTIR) method using Shimadzu at an infrared rang of $400-4000 \mathrm{~cm}^{-1}$.

\section{SEM analysis of silver nanoparticles}

The resulted dried powder of silver nanoparticles by green synthesis was subjected for SEM analysis, to determine the particle size of formed silver nanoparticles. The samples were sputter coated using $60 \%$ of gold and $40 \%$ of palladium and the images of nanoparticles were studied under SEM using Zeiss (EVO18) [12].

\section{RESULTS}

\section{Phytochemical screening of plant extracts}

The phytochemical screening of the four plant extracts showed the presence of carbohydrates, flavonoids, saponins, tannins, terpenoids, phenols and proteins. The result of the phytochemical analysis is shown in table 1. 
Table 1: Qualitative analysis of phytochemical components of B. acuminata and B. sensitivum leaf extracts

\begin{tabular}{|c|c|c|c|c|}
\hline Tests for & $\begin{array}{l}\text { B. acuminata } \\
\text { (Methanol extract) }\end{array}$ & $\begin{array}{l}\text { B. acuminata } \\
\text { (Aqueous extract) }\end{array}$ & $\begin{array}{l}\text { B. sensitivum } \\
\text { (Methanol extract) }\end{array}$ & $\begin{array}{l}\text { B. sensitivum } \\
\text { (Aqueous extract) }\end{array}$ \\
\hline Carbohydrates & $+\mathrm{ve}$ & $+\mathrm{ve}$ & $+\mathrm{ve}$ & $+\mathrm{ve}$ \\
\hline Flavonoids & $+\mathrm{ve}$ & $+\mathrm{ve}$ & $+\mathrm{ve}$ & $+\mathrm{ve}$ \\
\hline Phenols & $+\mathrm{ve}$ & $+\mathrm{ve}$ & $-\mathrm{ve}$ & $-\mathrm{ve}$ \\
\hline Proteins & -ve & -ve & -ve & -ve \\
\hline Saponins & $+\mathrm{ve}$ & -ve & $+\mathrm{ve}$ & - ve \\
\hline Tannins & + ve & $+\mathrm{ve}$ & $+\mathrm{ve}$ & -ve \\
\hline Terpenoids & + ve & $+\mathrm{ve}$ & $+\mathrm{ve}$ & -ve \\
\hline
\end{tabular}

\section{Nanoparticle synthesis}

The primary confirmation of silver nanoparticle formation was observed by the colour change in silver nitrate solution $(0.1$ mmol) on the addition of plant extracts. Test samples were compared with the standard, $0.1 \mathrm{mmol}$ silver nitrate solution i. e, white in colour. The aqueous extract and methanol extract of Bauhinia acuminata and Biophytum sensitivum showed the excellent result. Colour change was observed in the range of gold colour to light brown colour (methanol extract) and gold colour to dark brown colour (aqueous extract).

\begin{abstract}
Antioxidant assay-DPPH radical scavenging activity plant extracts and silver nanoparticles

The DPPH scavenging activity of antioxidant compounds are due to their hydrogen donating ability. The DPPH quenching activity of aqueous and methanol extracts of the plant and as well as nanoparticles was evaluated and compared with that of the standard ascorbic acid. The methanolic leaf extract of Bauhinia acuminata showed high DPPH scavenging activity of $90 \%$ (IC50 value 4.45 $\mu \mathrm{g} / \mathrm{ml}$ ). The methanolic leaf extract of Bauhinia accuminata (BAMP) exhibited maximum radical scavenging activity.
\end{abstract}

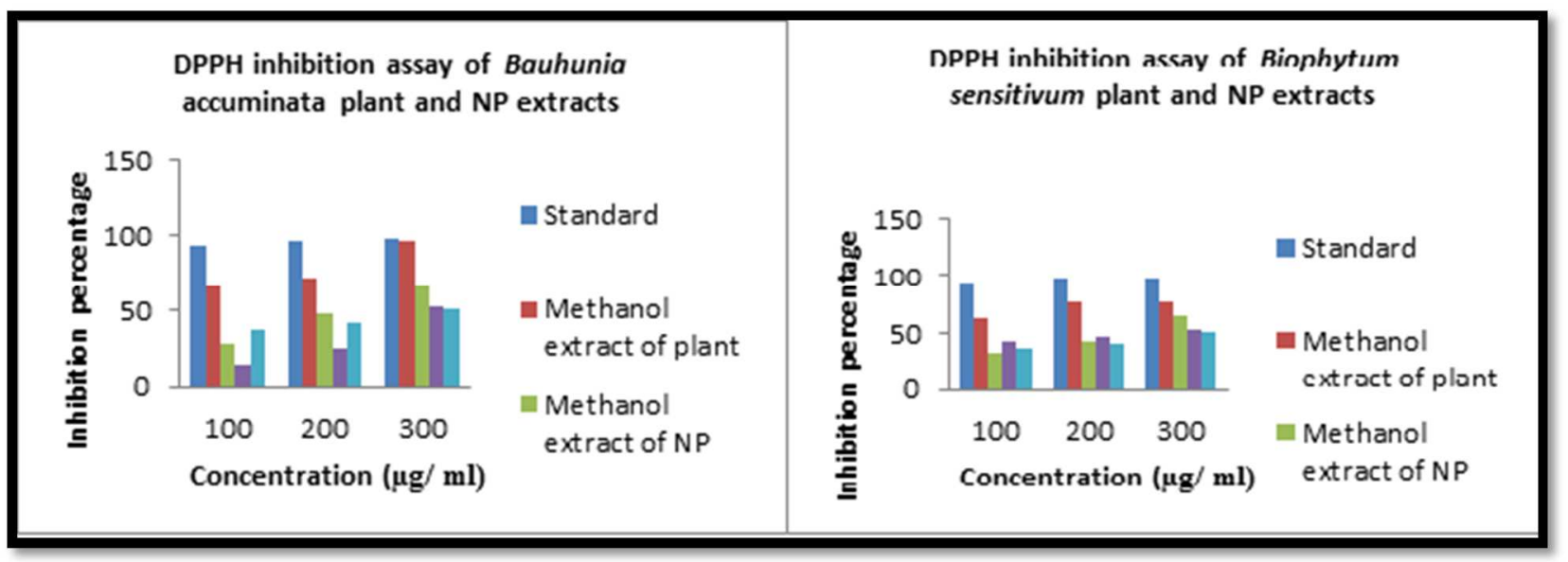

Fig. 1: DPPH assay of Bauhinia acuminata and Biophytumsensitivum extract and NP extracts

\section{Hemolytic assay of plant extracts and silver nanoparticles}

Haemolytic activity of leaf extracts of Bauhinia accuminata and Biophytum sensitivum and the nanoparticle (NP) extracts were performed to observe its toxic effects on human erythrocytes. The extracts showed low haemolytic activity. The percentage hemolysis was found in the range of 3\%-6.7\%. Thus, the extracts are found to be safe for human use.

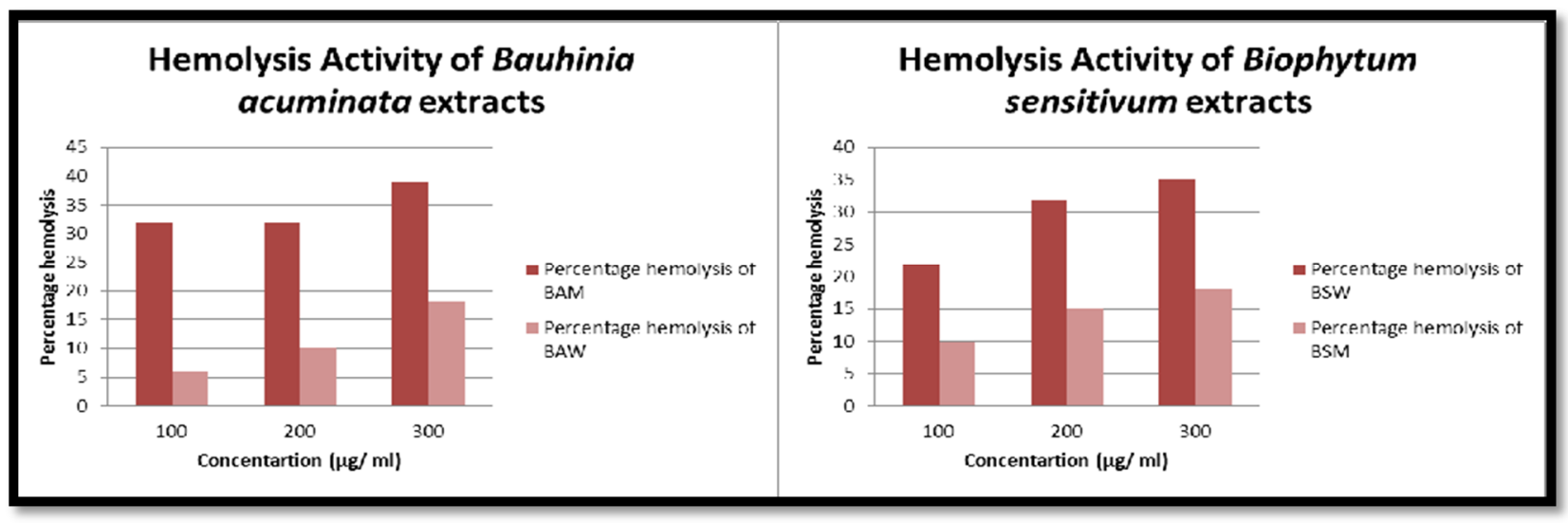

Fig. 2: Hemolysis assay of Bauhinia accuminata and Biophytumsensitivum leaf extract and NP extract 


\section{Antimicrobial activity of plant extracts and silver nanoparticles}

The anti-microbial activity was assessed using Kirby-Bauer method. The antimicrobial activity of methanolic as well as aqueous extracts of plant and silver nanoparticles were checked against some of the food pathogens like Bacillus cereus, Escherichia coli, Listeria monocytogens, Staphylococcus aureus and Rhizopussps. Extract dose of $1 \mathrm{mg} / \mathrm{ml}$ of
Bauhinia acuminate methanolic leaf extract showed excellent activity towards Bacillus cereus (inhibition zone $13 \mathrm{~mm}$ ). The methanolic leaf extract, as well as the silver nanoparticle of Biophytum sensitivum, showed the best activity towards Listeria monocytes (Inhibition zone $13 \mathrm{~mm}, 12 \mathrm{~mm})$. Other extracts showed moderate antagonistic activity. The leaf extract, as well as the silver nanoparticle, showed very weak activity towards the fungal strain.

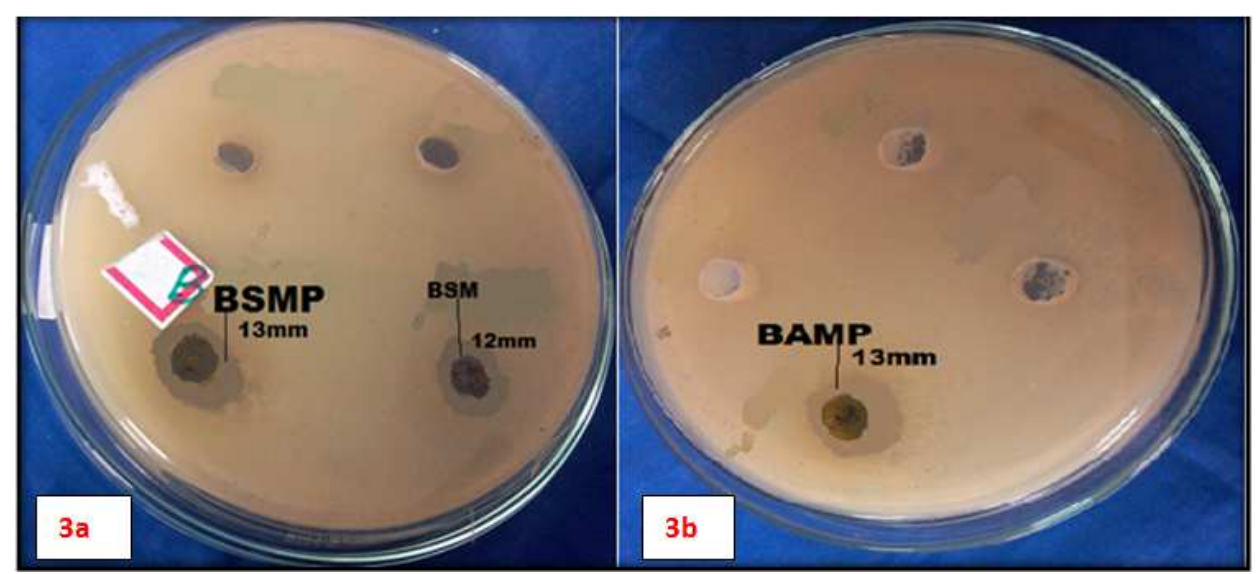

Fig. 3a: Antimicrobial activities of leaf extract and silver nanoparticle, 3b: Antimicrobial activity of plant leaf extract, Note: -BSMPBiophytum sensitivum methanolic plant extract, BSM-Biophytum sensitivum silver nanoparticle, BAMP-Bauhinia acuminata methanolic plant extract

\section{UV-visible spectroscopy characterization of silver nanoparticles}

UV-Visible absorption spectra of the silver nanoparticles in solution were recorded. The UV-Visible spectra of plant-mediated (Bauhinia

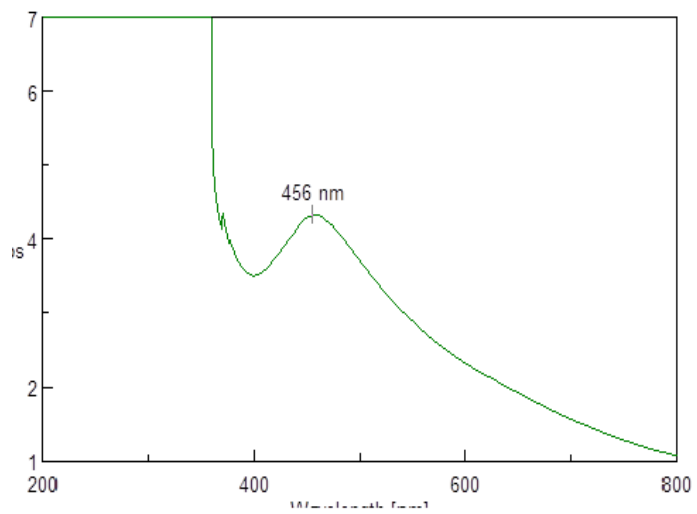

acuminata and Biophytum sensitivum) silver nanoparticles showed the excellent result. High peak of absorbance was observed between wavelengths of 400-460 $\mathrm{nm}$. The uv-visible absorption spectrum of the silver nanoparticles in solution is shown in fig. 4.

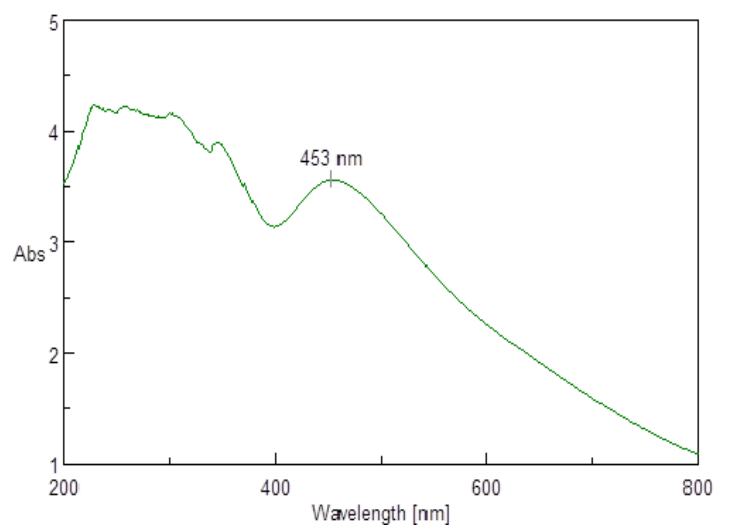

Fig. 4: UV-Visible spectra image of Bauhinia acuminata and Biophytum sensitivum

\section{Structural analysis of plant extracts and silver nanoparticles}

\section{GC-MS analysis}

The methanolic leaf extracts of the plants, Bauhinia acuminata and Biophytum sensitivum were undergone GC-MS analysis and showed the presence of DL-Alpha-Tocopherol and Alpha-Tocopherol-BetaD-Mannoside. All these compounds are proven to have excellent antioxidant, anti-cancer activities. The results are depicted in fig. 5 .

\section{FTIR (Fourier Transform Infrared Spectroscopy)}

FTIR analysis was done for the characterization of the resulted leaf extracts and nanoparticle extracts of Biophytum sensitivum as it showed high activity. The FTIR absorption spectra of Biophytum sensitivum extracts of the plant as well as nanoparticles were found to be in a range of $981.77 \mathrm{~cm}^{-1}$ $3317.56^{-1}$. These absorption bands correspond to various functional groups of amides, aromatic rings, nitro groups, esters, alkenes, aldehydes, amines, etc. The amide, carboxyl, hydroxyl, aromatic groups i. e, the phenols, saponins, terpenoids found in the plant extracts are responsible for the reduction and capping during the silver nanoparticle synthesis. The FTIR results of the plant and nanoparticle extracts are shown in table 2 .

\section{SEM analysis}

The SEM image is employed to predict the size and morphology of resultant silver nanoparticles. It was observed that most of the nanoparticles are spherical in shape with an average diameter of 2 micrometers $(\mu \mathrm{m})$. 


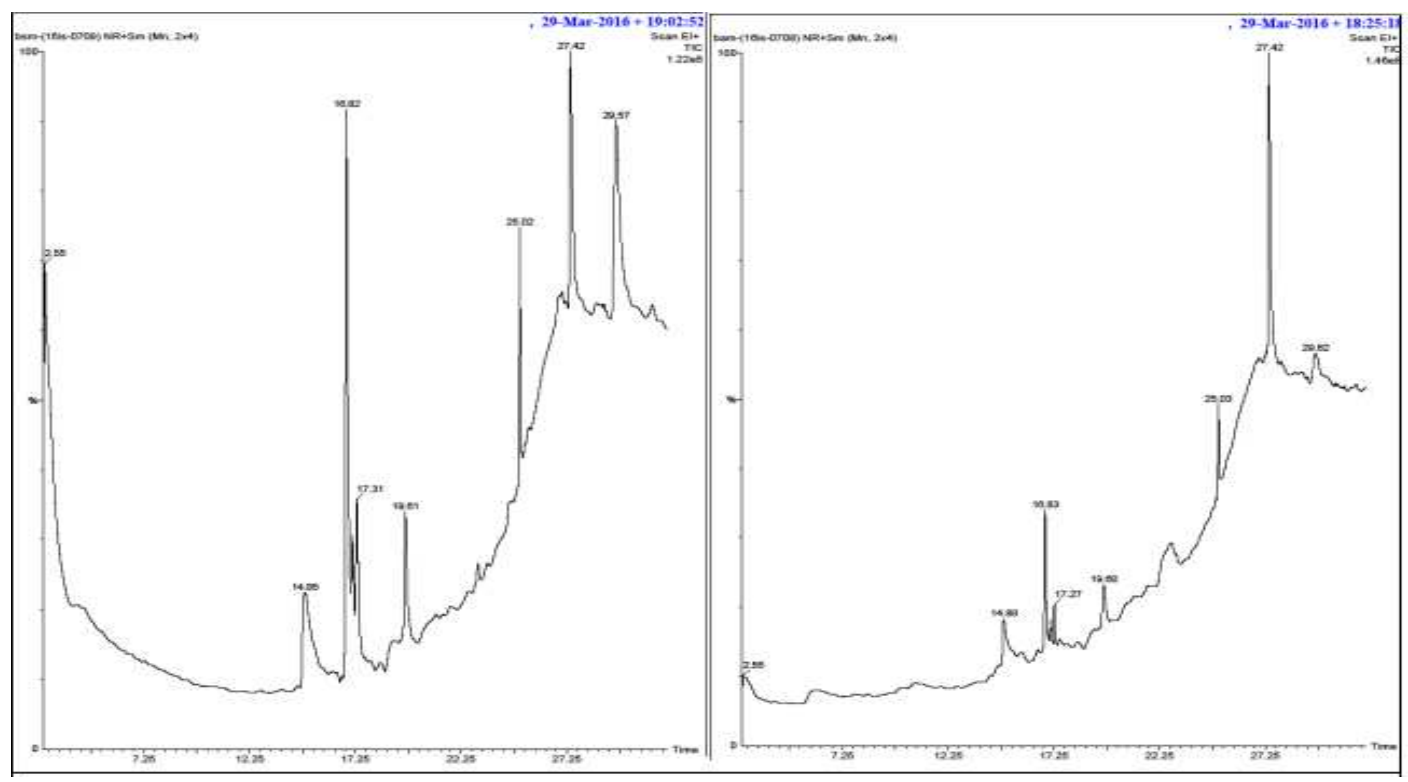

Fig. 5: GC-MS analysis of Bauhinia acuminata and Biophytum sensitivum methanol leaf extract

Table 2: FTIR spectral peaks and its functional groups and vibrations

\begin{tabular}{llll}
\hline Extracts & Absorption & Functional group & Type of vibration \\
\hline \multirow{3}{*}{ BSWP } & 3304.06 & Amides & $\mathrm{N}-\mathrm{H}$ stretch \\
& 1581.63 & Aromatic rings & $\mathrm{C}-\mathrm{C}=\mathrm{C}$ stretch \\
& 1382.96 & Nitro groups & $\mathrm{N}=\mathrm{O}$ bend \\
BSMP & 1020.34 & Esters & $\mathrm{C}-\mathrm{O}$ stretch \\
& 3234.62 & Carboxylic acids & O-H stretch \\
& 3186.40 & Alkenes & Triple bond C-H \\
& 2924.09 & Alkanes & C-H stretch \\
& 2852.72 & Carboxylic acid & O-H stretch \\
& 1604.77 & Alkenes & C-C=C stretch \\
& 1442.75 & Alkanes & H-C-H bend \\
& 1377.17 & Alkanes & CH C-H bend \\
BSW & 1265.30 & Alkyl halides & C-F stretch \\
& 1043.49 & Alcohol & C-O stretch \\
BSM & 1722.43 & Aldehydes & C=O stretch \\
& 1620.21 & Alkenes & C-C=C stretch \\
& 1028.06 & Ethers & T-O-C-C-O stretch \\
& 3317.56 & Alkynes & Triple bond C-H bend \\
& 2916.37 & Alkanes & And symmetric \\
& 2860.79 & Carboxylic acid & O-H stretch \\
& 1722.43 & Aldehydes & C=O stretch \\
& 1598.99 & Amides & N-H bend \\
& 1371.39 & Alkane & CH C-H bend \\
& 1253.73 & Alkyl halides & C-F stretch \\
& 981.77 & Alkenes & =-H bend \\
\hline
\end{tabular}

Note: BAMP-Bauhinia acuminata methanolic leaf extract, BSMP-Biophytum sensitivum methanolic leaf extract, BAM-Bauhinia acuminata derived silver nanoparticles, BSM-Biophytumsensitivum derived silver nanoparticles.
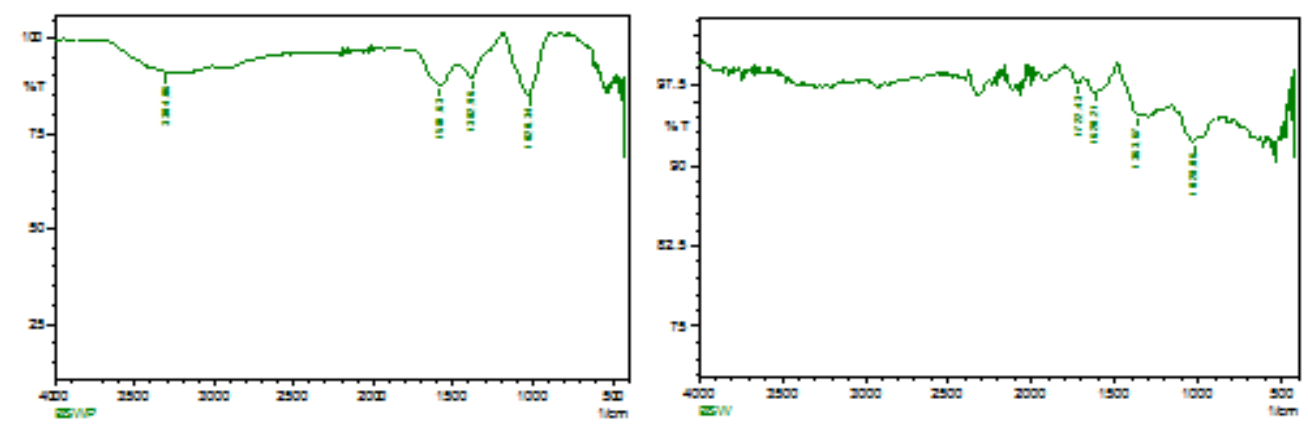

Fig. 6: FTIR spectra of Biophytum sensitivum plant extract (aqueous extract) and nanoparticles 

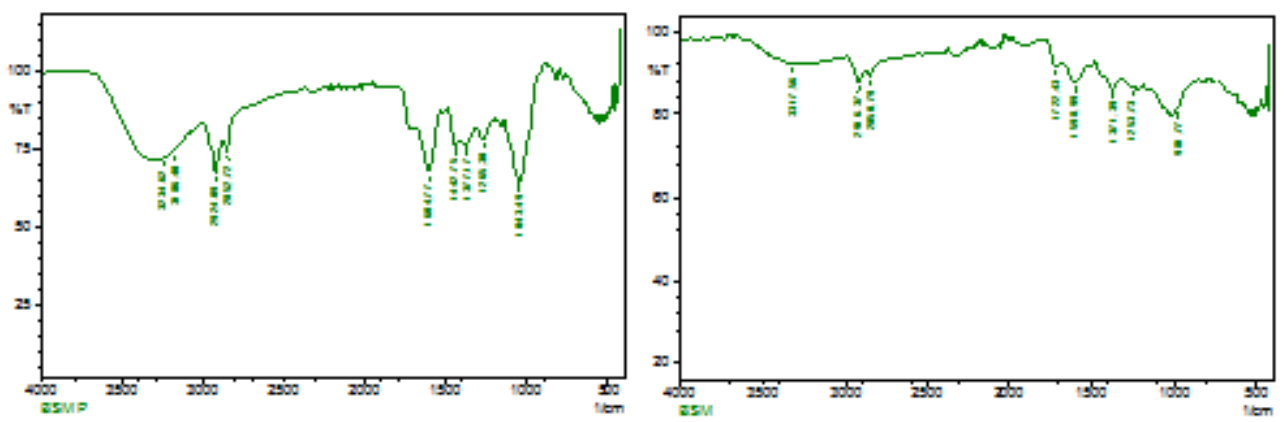

Fig. 7: FTIR spectra of Biophytum sensitivum plant extract (methanol extract) and nanoparticles

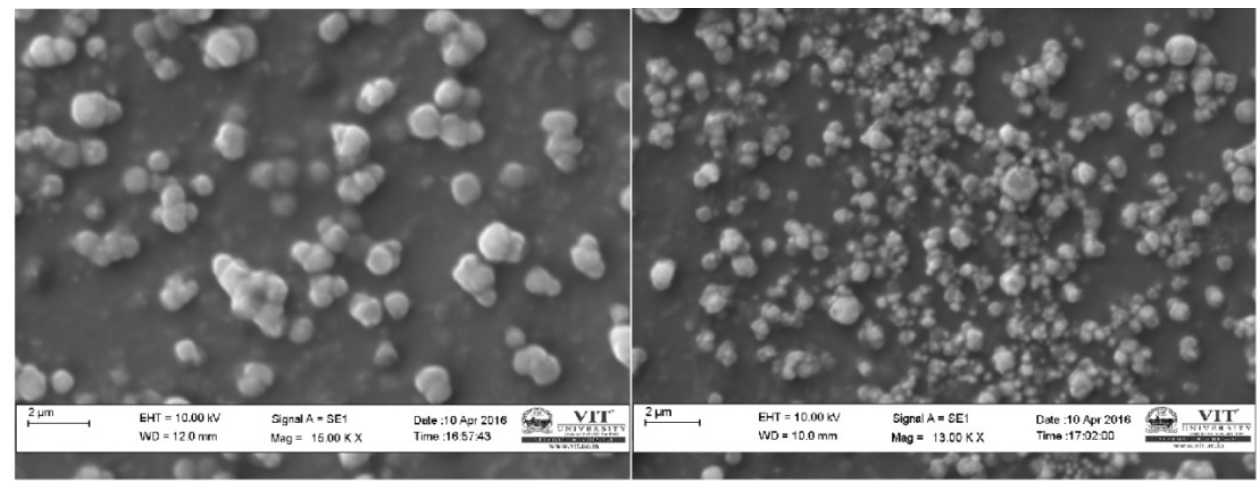

Fig. 8: SEM image of Bauhinia acuminata aqueous extract

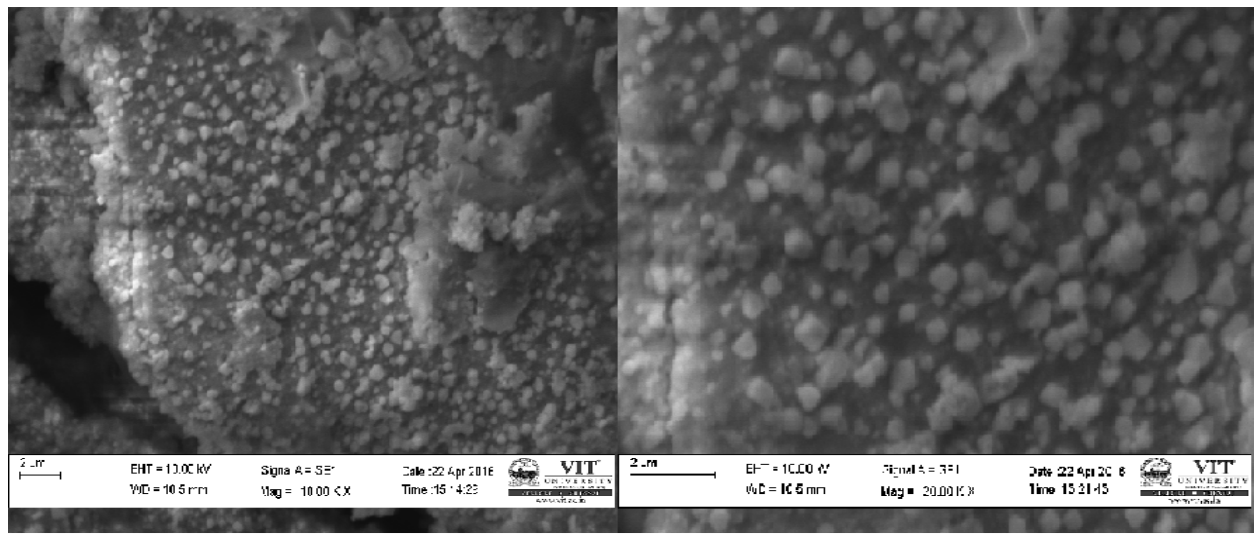

Fig. 9: SEM image of Bauhinia acuminata methanol extract

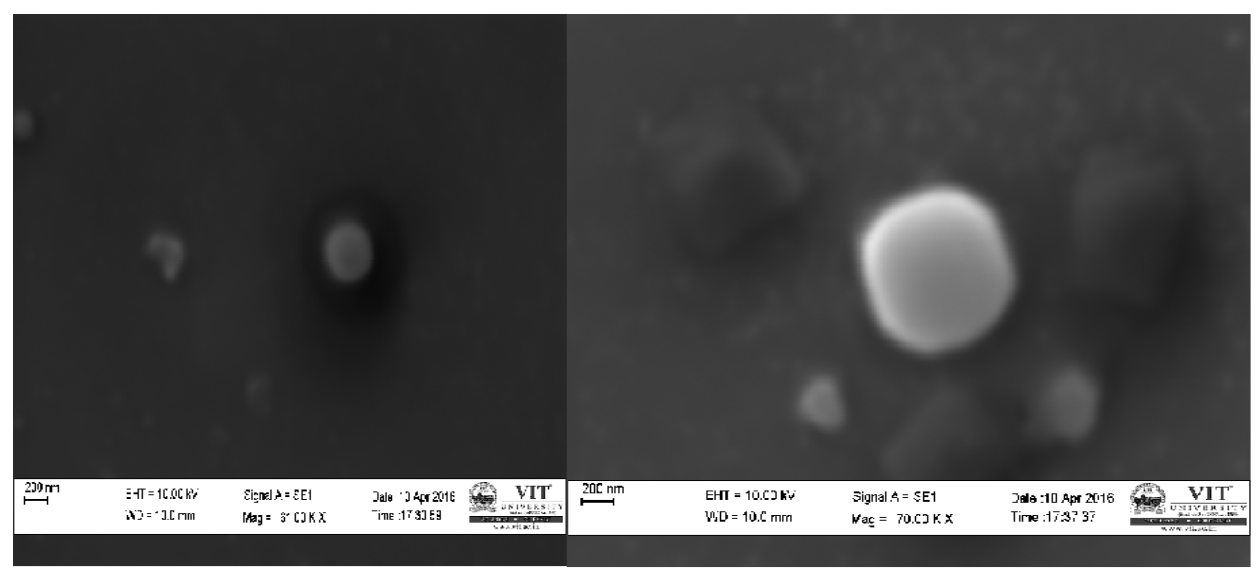

Fig. 10: SEM image of Biophytum sensitivum aqueous extract 


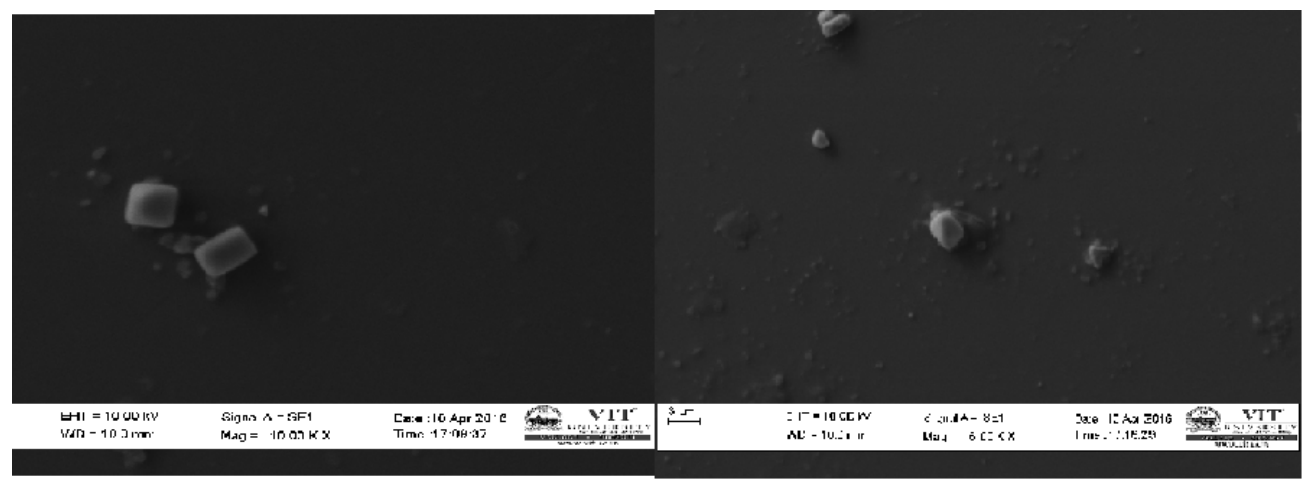

Fig. 11: SEM image of Biophytum sensitivum methanol extract

\section{DISCUSSION}

Plant-based compounds have a pharmacological activity for the prevention and treatment of complex diseases. Therefore, the researcher provides special attention to the plant derived metabolites. The antimicrobial, anticancer and antioxidant properties of the medicinal plants depend on the presence of its secondary metabolites viz., phenolic acids, flavonoids, tannins, coumarins, lignins, quinones, stilbenes and curcuminoids [13].

The secondary metabolites of plants are used as antioxidants, antiblood clotting agents, food additives, in the preparation of cosmetics, etc. The result of the present study showed that the aqueous extracts of Biophytum sensitivum have showed the presence of flavonoids and carbohydrates. The results of the present study coincided with previous observations and supported the pharmacological evidence. There is a contradictory in the case of Bauhinia acuminata, the present study shows the presence of flavonoids in methanolic leaf extract and presence of terpenoids in both aqueous as well as in methanolic extract [14].

In the present study, the methanol extract of Bauhinia acuminata showed high DPPH scavenging activity of $90 \%$ whereas the DPPH scavenging percentage in a previous study was found to be $84 \%$ [15]. Kalita et al. observed the maximum DPPH scavenging activity of 43.96 in Biophytum leaf extract, while in the present study we observed the inhibition percentage of $76 \%$ [16]. Hemolytic activity of plant extracts in the present study showed less haemolytic activity.

The structural analysis of plant extracts using GC-MS revealed the presence of pharmacologically important compounds like tocopherols, phenols, diethyl halite, phytol, etc. which has proven antioxidant, anti-cancer, anti-microbial, anti-inflammatory activities. Previous studies showed the presence of cinnamic acid, homogentisic acid, $p$-hydroxybenzoic acid, vanillic acid, gentisic acid, $p$-coumaric acid, protocatechuic acid; $p$-coumaric acidetc [17]. The compounds differ, but the functions they serve are similar to each other.

Due to the increased resistance of microorganisms to conventional drugs, it's important to discover new solutions to prevent the development of multiresistant strains. Plant-derived compounds are a substitute for conventional drugs. The antimicrobial activity of the methanolic leaf extract of Bauhinia acuminata in the present study exhibited satisfactory activity towards food pathogens like Bacillus cereus and Listeria monocytogens, Staphylococcus aureus and Escherichia coli. The antimicrobial activity of Biophytum sensitivum was compared with previous reports and found coinciding [18].

The present study emphasise the synthesis of the silver nanoparticle using leaf extracts of Bauhinia acuminata and Biophytum sensitivum, no reports on these plant's ability to synthesise nanoparticles have been reported to our knowledge till date. When comparing with the previous studies regarding plant-mediated silver nanoparticle synthesis, the present work has more significance due to its application of resultant silver nanoparticle in various studies like antioxidant assay, haemolytic assay and antimicrobial assay against food pathogens. The free radical scavenging activity of silver nanoparticle in the present work was found to be $67 \%, 65 \%, 53 \%$. The overall results shows that the plant extracts exhibited more activity than silver nanoparticles synthesised from the medicinal plants Bauhinia acuminata and Biophytum senistivum.

\section{CONCLUSION}

The present investigations suggest that the plant extracts, as well as the silver nanoparticles, showed a good result of antioxidant activity, haemolytic activity. It was found that the high rates of phytochemicals are widely distributed in Bauhinia acuminata and Biophytum sensitivum. The plant extracts exhibited the presence of flavonoids, saponins, carbohydrates, tannins, terpenoids, etc. These compounds are the sources that render pharmacological activities to the plant. The structural analysis yielded pharmacologically important compounds like DL-alpha tocopherol, which is proven to have a wide range of antioxidant, anti-cancer, anti-inflammatory activities. They are also used in food industry, cosmetic industry, etc. The most important significance of the present work is the synthesis of silver nanoparticles from these less explored medicinal plants. This current investigation is the first reported case of silver nanoparticles from Bauhinia acuminata and Biophytum sensitivum.

These plants can be exploited further to undergo more research. The nanoparticle synthesises using Bauhinia acuminata and Biophytum sensitivum can be widened to get better yield in synthesis and activity. In future, the silver nanoparticle from these plants can be used as potent therapeutical agents and can be further exploited for their other beneficial effects in the pharmacological studies. Thus from this current study, we can conclude that the plant extracts can be used as potent therapeutics than silver nanoparticles.

\section{CONFLICT OF INTERESTS}

\section{Declared none}

\section{REFERENCES}

1. Akhila Sravya Dantu, Shankarguru P, Ramya devi D, Vedha Hari $\mathrm{Bn}$. Evaluation of in vitro anticancer activity of hydroalcoholic extract of Tabernaemontana divaricate. Asian J Pharm Clin Res 2012;5:59-61.

2. Ashokkumar S, Ravi S, Kathiravan V, Velmurugan S. Synthesis of silver nanoparticles using $A$. indicum leaf extract and their antibacterial activity. Spectrochim Acta Part A 2015;134:34-9.

3. Kanchana R, Pranjita Zantye. Plant-mediated synthesis of silver nanoparticles with diverse applications. Asian J Pharm Clin Res 2016;9:159-63.

4. Khandelwal N, Kaur G, Kumara N, Tiwari A. Application of silver nanoparticles in viral inhibition: a new hope for antivirals. Dig J Nanomater Biostruct 2014;9:175.

5. Park S, Park HH, Kim SY, Kim SJ, Woo K, Ko G. Antiviral properties of silver nanoparticles on a magnetic hybrid colloid. Appl Environ Microbiol 2014;80:2343-50.

6. Anju Krishna SR, Hafza S, Poorna Chandrika G, Lekhya Priya C, Bhaskara Rao KV. Pharmacological properties, phytochemical and GC-MS analysis of Bauhinia acuminata Linn. J Chem Pharm Res 2015;7:372-80. 
7. Arokiya FAA, Arumugam R, Saravanan S, Anantharaman P. Photofabrication of gold nanoparticles assisted by leaves of Suaedamonica and its free radical scavenging property. J Photochem Photobiol B: Biol 2014;135:75-80.

8. Pannerselvam, Balashanmugam, Pudupalayam T, Kalaichelvan. Biosynthesis characterization of silver nanoparticles using Cassia roxburghii $D C$ aqueous extract and coated on cotton cloth for effective antibacterial activity. Int J Nanomed 2015;10:87-97.

9. Harbone JB. Phytochemical methods, a guide to modern techniques of plant analysis. Chapman and Hall, London; 1973.

10. Blios MS. Antioxidant determination by the use of a stable free radical. Nature 1958;29:1199-200.

11. Priya CL, Gaurav K, Bhaskara RKV. Antioxidant activity of Achyranthesaspera Linn stems extracts. Pharmacologyonline 2010;2:228-37.

12. Krishnaraj C, Jagan EC, Rajasekar S, Selvakumar P, Kalaichelvan PT, Mohan N. Synthesis of silver nanoparticles using Acalyphaindica leaf extract and its antibacterial activity against water borne pathogens. Collid Surf B: Biointer 2010;76:50-6.

13. Cai Y, Luo Q, Sun M, Corke H. Antioxidant activity and phenolic compounds of 112 traditional Chinese medicinal plants associated with anticancer. Life Sci 2004;74:2175-84.
14. Anjukrishna SR, Hafza S, Poorna CG, Lekhya PC, Bhaskara RKV. Pharmacological properties, phytochemical and GC-MS analysis of Bauhinia acuminata Linn. J. Chem Pharm Res 2015;7:372-80.

15. Anjukrishna SR, Hafza S, Poorna CG, Lekhya PC, Bhaskara RKV. Pharmacological properties, phytochemical and GC-MS analysis of Bauhinia acuminata Linn. J Chem Pharm Res 2015;7:372-80.

16. Venkata NK, Tadi R, Sudhakara RP, Sandeep BV. Assessment of phytoconstituents composition and anti-haemolytic activity of Psidiumguajava leaf extract against $\mathrm{H} 2 \mathrm{O} 2$ induced hemolysis in chicken erythrocytes. Int J Pharm Sci Res 2016;1:27-30.

17. Charalampos P, Michael. Analysis of naturally occurring phenolic compounds in aromatic plants by RP-HPLC coupled to diode array detector (DAD) and GC-MS after Silylation, Foods. Foods 2013;2:90-9.

18. Anjukrishna SR, Hafza S, Poorna CG, Lekhya PC, Bhaskara RKV. Pharmacological properties, phytochemical and GC-MS analysis of Bauhinia acuminata Linn. J Chem Pharm Res 2015;7:372-80.

\section{How to cite this article}

- Elizabath Antony, Mythili Sathiavelu, Sathiavelu Arunachalam. Synthesis of silver nanoparticles from the medicinal plant bauhinia acuminata and biophytum sensitivum-a comparative study of its biological activities with plant extract. Int J Appl Pharm 2017;9(1):22-29. 